Revista de la red interuniversitaria de estudios sobre las literaturas rioplatenses contemporáneas en Francia

$9 \mid 2013$

Homenaje a Ana María Barrenechea

\title{
Disociación discursiva : Dos bocas
}

Noé Jitrik

(2) OpenEdition

Journals

Edición electrónica

URL: http://journals.openedition.org/lirico/1106

DOI: $10.4000 /$ lirico. 1106

ISSN: 2262-8339

Editor

Réseau interuniversitaire d'étude des littératures contemporaines du Río de la Plata

Referencia electrónica

Noé Jitrik, «Disociación discursiva : Dos bocas », Cuadernos LIRICO [En línea], 9 | 2013, Puesto en línea el 01 septiembre 2013, consultado el 03 mayo 2019. URL : http://journals.openedition.org/lirico/1106 ; DOI : 10.4000/lirico.1106

Este documento fue generado automáticamente el 3 mayo 2019.

\section{(c) $(\mathbb{0} \Theta \Theta$}

Cuadernos LIRICO está distribuido bajo una Licencia Creative Commons Atribución-NoComercialSinDerivar 4.0 Internacional. 


\title{
Disociación discursiva : Dos bocas
}

\author{
Noé Jitrik
}

1.

1 Dos escenas, registradas en diferentes anales, me parecen decisivas para comprender la índole de lo que llamamos "discurso" si por tal cosa entendemos una manifestación verbal que tiene efectos sobre el orden de lo real. La primera, histórica, es la que protagoniza V. I. Lenin, subido a un tren, arengando a la multitud en las vísperas de la revolución que terminaría con la vetusta monarquía rusa; en la segunda, más cercana, aparece Juan D. Perón al llegar a la Argentina, después de un exilio de diecisiete años.

2 En ambos casos, palabras salidas de la boca de esos prestigiosos emisores, producen hechos indudables más allá de su emisión ; en el primero, los enunciados se refieren a una realidad verificable, la de un pasado que hay que abolir, y a una realidad probable, la de una nueva sociedad que debe empezar a existir a partir de esas palabras poderosas, explícitas e irrefutables que mueven a millares de personas a tomar las armas, a ocupar palacios, a ajusticiar, incluso, a nobles y burgueses hasta entonces dueños de todo, de vidas y haciendas, a ocupar su lugar en una sociedad atrasada e injusta. En el segundo, podría decirse que el efecto es diferido pero igualmente claro : "Me quiero ir a mi casa", dice el político que viene del exilio cuando, apenas bajado del avión, lo han internado en un hotel y no lo dejan salir de inmediato pero, apenas ese infantil pedido se hace público, se produce un movimiento de tropas y de tanques. Se diría que en ambas situaciones la palabra hace milagros, mueve montañas, como preconiza una vieja sabiduría pero, más concretamente, actúa sobre la realidad y lo que eran hechos verbales, cada uno a su manera, devienen en un conjunto de hechos físicos que se ejecutan sobre determinados seres humanos que se mueven y mueven cosas.

3 No importa lo que en cada una de esas escenas hay de trascendencia histórica ni tampoco se trata de hacer comparaciones, entre una revolución socialista o comunista, tan universalmente exaltada, celebrada y denostada, y una jugada liberal-democrática, tan local; importa, en cambio, lo que tienen en común, meros ejemplos fácilmente reconocibles de innumerables situaciones semejantes. $Y$ eso, lo que tienen en común, es 
que permiten distinguir concretamente el rasgo principal de esa entidad llamada "discurso" sobre la cual se ha puesto mucha atención en las cuatro últimas décadas. En pocas palabras, lo que señalamos al comienzo, "una articulación verbal que produce efectos no verbales más allá de ella, en las cosas que refiere y aun más allá de ellas", cobra toda su validez, es como si esas dos escenas constituyeran una prueba del acierto de una definición.

4 Pero de aquí se desprenden otros temas que no deberían ser rechazados. El primero es el relativo a los emisores, tan prominentes por su historia, su asentada personalidad, el papel que desempeñaron en el ámbito en el cual se inscribieron las respectivas escenas y, más aún, en la sociedad en su conjunto, para la cual cualquier cosa emanada de ellos sería considerada, tenida en cuenta y en ciertos casos seguida. De ello se infiere que las respectivas calificaciones que se les aplican tienen mucho que ver con los efectos producidos por sus discursos ; las mismas frases, emitidas por sujetos "indiferentes", no tan caracterizados o nada caracterizados, harían un discurso "inerte" y evanescente, algo así como "charlas de café o discusiones de sobremesa". De lo cual surgiría un rasgo discursivo que al mismo tiempo sería un requisito inherente al modo de ser de los discursos en general o, más precisamente, del objeto designado como "Discurso".

El segundo concierne a los receptores; si son indiferentes a la emisión el discurso no se constituye, en tanto que si son sensibles a ella, porque creen en el emisor o porque están esperando un mensaje como el que reciben, el efecto previsto en su capacidad tiene lugar y hay discurso en su sentido pleno.

6 Y si hablamos de escena, no podemos limitarnos sólo a los elementos externos, teatrales, que la palabra "escena" comporta ; aquí, "escena" es empleada metafóricamente y puede ser entendida como conjunto que incluye, ya lo hemos considerado, un emisor, receptores (las frases no son lanzadas en una habitación cerrada sino en espacios públicos) y, ciertamente también, una determinada circunstancia motivadora, en el caso de Lenin la situación prerrevolucionaria, en el de Perón, las expectativas políticas que su regreso podría satisfacer.

7 Una hipótesis posible es que la reunión de todos esos factores explica las consecuencias que tienen los respectivos discursos y que se cumplen de este modo en plenitud; en otras y sencillas palabras, que un hecho verbal tenga efecto sobre lo no verbal, y no sólo porque existe la ilocutoriedad, o sea los verbos que implican la acción que indican ("Hacer cosas con palabras" proclamó revolucionariamente J. L. Austin), es posible a causa de la concurrencia de tales factores, aunque en ocasiones puede producirse una frustración.

Pero, además, que el punto de partida de este razonamiento hayan sido situaciones de índole claramente política que, desde luego, tienen un alto grado de generalidad, no quiere decir que en otras instancias las cosas funcionen de un modo muy diferente ; eso permite pensar que hay "campos" en los cuales las respectivas escenas conducen a la misma conclusión aunque las modalidades y los objetivos sean distantes unos de otros: ¿qué se quiere lograr con un discurso político y qué con uno literario o religioso?

9 En cuanto al discurso en sí mismo, eso no es todo. Los razonamientos precedentes ponen en evidencia que el discurso, cuya identidad teórica hemos diseñado, no está solo ; así, si los efectos que puede tener son las acciones que se lleven a cabo, en términos amplios el despliegue revolucionario en un caso, el despliegue de tropas en el otro, al mismo tiempo, como no hay acción en sí misma y en el aire, tales acciones se encarnan en objetos sobre los que actúan, las armas en un caso, los tanques en el otro. Esto quiere decir, traduciendo 
los términos, que la sociedad se mueve en un conjunto de tres instancias, ObjetosAcciones-Discursos, aunque desde luego, considerando que hay emisores y circunstancias, voluntades, deseos, sueños, ideas, propósitos, pasiones que sin duda determinan la puesta en marcha de esas tres instancias básicas.

Pero, ¿qué son las acciones? El modo de presentarlas como efecto inmediato puede reducir el concepto ; en realidad entendemos aquí por "acciones" algo mucho más amplio, todo aquello que se ejecuta en una sociedad y que satura el discurso o, dicho de otro modo, que el discurso, aun sin nombrarlo, lo incluye o lo considera. Del mismo modo y simétricamente, ¿qué son objetos? Sin homologar la expresión a "cosas", podríamos aventurar que son las concreciones formalizadas con las que se maneja una sociedad y cuyo carácter puede ser tanto físico como abstracto y simbólico.

11 Es cierto que los discursos, por esa razón, también son objetos (cuando son escritos sobre todo, "res non verba"; cuando no, las palabras son vanas, no tienen peso, son "palabras que se lleva el viento"), muy abundantes y variados -plurales clasificaciones lo muestran-, y también pueden ser acciones que alguien, un sujeto individual o colectivo, ejecuta, así lo muestran los trabajos de los escritores o de los parlamentarios o de los sacerdotes. Hay que tener en cuenta, por otra parte, que los discursos poseen identidad, mayor o menor peso significativo y que su configuración descansa no sólo sobre una retórica, que le da su forma, sino también sobre una carga semántica y semiótica que se alimenta de una historia o la niega.

Esto no quiere decir que los tres conceptos se diluyan de manera tal que parezca que en verdad no hay diferencia entre discursos, objetos y acciones: en una perspectiva discursiva esta itinerancia entre los tres aspectos debe ser vista de otro modo puesto que los discursos son objetos de un tipo particular, y como acciones transcurren en un ámbito igualmente otro respecto de las que se llevan a cabo en la sociedad humana misma. El concepto de discurso, admitiendo tales tránsitos pero sin renunciar a las diferencias entre palabras, acciones y objetos que, por cierto, se expresan espontánea e indiscutiblemente en una perspectiva ideológico-política el lugar común orgulloso y declarativo "hechos, no palabras" ; en una lingüístico-filosófica el perturbador conflicto entre "palabras y cosas", una apasionante pareja problemática-, promete una posibilidad de análisis concretos igualmente diferentes.

De modo que si, como se dijo al principio, la reunión de todos esos factores, palabras, emisor, receptores y circunstancias explica la función que pueden cumplir los respectivos discursos, ahora podríamos completar el universo añadiendo la tríada "objetos/acciones/ discursos", como lo que recorre el espacio social, lo cual nos permitiría considerar situaciones particulares y explicarnos qué puede estar ocurriendo en determinados discursos, de gran presencia en la sociedad pero que navegan en particulares crisis en cuanto al logro que perseguirían.

\section{2.}

14 No carece de posibilidades analíticas la peculiar frase de Perón. Ya lo señalamos, parece reproducir, pero no paródicamente, un pedido infantil que, como tal y en su circunstancia propia, suele ser o bien satisfecho de inmediato, por parientes o amigos considerados, o bien pospuesto provisoriamente, por parientes o amigos parsimoniosos, o bien indefinidamente por secuestradores o carceleros. Si quien lo enuncia se siente en este 
último caso, más que un pedido sería una denuncia, ambigua porque oficialmente el emisor no está preso, tampoco apela a parientes o amigos y la satisfacción del pedido tiene menos importancia que lo que puede provocar la suposición sobre ese momento indeciso. Que es doble : por un lado, la reacción de los partidarios, que esperan el regreso del líder desterrado con la ansiedad de una reivindicación histórica; por el otro, la de quienes quieren neutralizar tal reacción y hacer conocer al emisor de la frase que le están poniendo límites, en otras palabras que su regreso no es con toda la gloria que imagina. En todo caso, pero en la situación discursiva, la coherencia es total entre discurso, o sea la frase, las acciones, o sea lo que la frase desencadena, y objetos, tanto los tanques y las tropas que toman posición como las consecuencias políticas para el país entero que estarían contenidas implícitamente en la frase.

Esa coherencia se inscribe en una historia aunque la frase no tenga un contenido doctrinario, cosa que se espera de un político de envergadura, ni propositivo en ningún sentido ; su virtud reside en que permite ir un poco más allá y pensar que si tiene eficacia es porque está vinculada (no por la frase como tal, en apariencia caprichosa) con el discurso propio e histórico de quien en un momento de gran tensión política la emite $y$, sin duda, con la circunstancia, un gran movimiento de masas, una dictadura a punto de bajar las armas, una suerte de reconciliación de numerosos sectores de la vida argentina con quien había sido objeto de fuertes tomas de distancia durante dos décadas.

En cuanto a tal discurso personal e histórico, podría decirse que antes de comenzar a operar en el sentido que lo hizo célebre seguramente también poseía coherencia, aunque de otro tipo ; en la posición del emisor como militar sus enunciados -seguramente en sus clases pero también en sus cartas y documentos conspirativos- tenían determinado alcance pedagógico, tendían estratégicamente a proponer acciones a realizar, pero en un campo delimitado, cuyas previsibles o deseables consecuencias deberían afectar personas e instituciones, o sea, en nuestra terminología, "objetos". Posteriormente, una vez obtenido un nuevo lugar de enunciación, un sitio de poder que Perón construyó con gran visión, el discurso es otro y la coherencia que sin duda poseía, a juzgar por sus efectos, hay que buscarla en otra parte.

La tuvo : como en ningún momento los tres términos en cuestión se dislocaron, se podía pensar, o juzgar, que la clave que había encontrado - ya como producto de un pensamiento largamente amasado, o bien por una inspiración de momento sostenida por una percepción de un estado social crítico, o bien, por último, como sabia aplicación de estrategias exitosas en otros lugares (el varguismo, el fascismo, el cardenismo, de diferente signo)- se había mantenido incólume hasta el final de su vida pese a haber tenido que adaptarse, forzosamente, a un discurso estatal e institucional en el momento del poder; dicho sea de paso, esta situación es previsible en todo discurso vinculado a estrategias globales, ningún discurso político, que puede ser circunstancial, más o menos doctrinario o teórico, permanece igual a sí mismo si sus emisores alcanzan el éxito y logran operar desde el Estado que, desde antes de que el concepto fuera formulado, poseía ya un discurso, que designaremos como "estatalista", del cual lo menos que puede decirse es que era y es estructurado, rígido y saturado de referencias internas cuya razón, aparentemente, es sostenerlo. De ahí su fuerza, neutralizadora, y la dificultad de reducirlo o neutralizarlo.

18 Se dirá, y se dijo, volviendo a Perón, que ese discurso era básicamente pragmático y que por eso su capacidad de reunir acciones y objetos funcionó en cualquier circunstancia, a lo largo de los años, sostenido o no por instrumentos de poder y no de pura convicción, 
pero no se ha recalcado suficientemente que se constituyó renunciando al precedente -lo cual de todos modos implicaba un arrojarse al vacío y salirse de la gran sombrilla del discurso militar-, apropiándose de otros que no habían logrado esa coherencia, añadiéndolos al primigenio autoritarismo militar: anarquismo obrerista, catolicismo filosófico, comunismo centralista, socialismo estatalista, conservadurismo ordenador, desarrollismo económico, radicalismo político, nacionalismo cultural, una sabia combinación que le permitió recuperar tradiciones y postular innovaciones. Los respectivos aunque parciales elementos provenientes de esos lugares parecían haber sido sometidos a un proceso químico que los trasmutaba y daba lugar a una única voz capaz de tocar resortes de los más diversos sectores sociales, conformando a unos, humillando a otros, enfrentando a unos, aliándose con otros, cooptando a unos, alejando a otros, siempre con enunciados cuyas referencias eran determinados objetos y sus efectos buscados acciones correlativas sobre objetos existentes o probables.

No podría decirse, sin embargo, que ese discurso era el de un sistema: de ahí que se le haya endilgado con alguna reiteración el mote de "oportunista". Y si en vida de Perón su discurso se caracterizó por su coherencia, luego de su muerte empezó a ser amenazado en sus prolongaciones por una disociación indetenible: el discurso devino invocativo, las acciones a que convocaba eran a lo sumo propias de un Estado y su administración o de intereses exclusivamente partidarios, no de sus propuestas iniciales, y los objetos a los que se refiere o a los que apunta se agrupan en una multitud de categorías -diversos grupos, diversos intereses- a las que atiende antagonizando a veces a unas con otras.

Podría decirse, en cambio, que el discurso de Lenín, no sólo considerando la escena inicial sino in toto, postulaba un sistema en el que acciones, objetos y palabras, en el sentido que les estamos dando, estaban estrechamente soldados. Sin embargo, la disociación acechó igualmente a su herencia. Durante un tiempo, ese discurso cuya coherencia había sido demoledora, funcionó junto a un creciente e inevitable lenguaje estatal sin degradarse demasiado y sin perder su carácter primero en razón de que el Estado concebido por tal discurso era inaugural, no se hacía cargo de su precedente discursividad: las antiguas instituciones no habían sido retomadas y, por el contrario, había que crear nuevas, acordes con el discurso inicial que tenía la fuerza de una fundación. Pero eso va cambiando a medida que se produce un paulatino predominio del nuevo Estado, en proceso de consolidación y en una creciente actitud defensiva; los objetos que saturan el discurso se particularizan, ya no tienen el alcance holístico que tenían, y las acciones que atienden a ello son reducidamente propiciadoras, someten al discurso a incesantes justificaciones de necesidad o bien a amenazadoras perspectivas; el discurso leninista deviene estatalista, y esto lo sofoca, lo recluye y lo hace obligatorio y canónico ; esa modificación se da quizás antes del estalinismo pero a partir del estalinismo y el correlativo aparato de control social, historia harto conocida, no tiene vuelta atrás. En el plano en el que estamos discurriendo se produce una evidente y perturbadora disociación, cuyas consecuencias no son sólo discursivas sino relativas a vidas humanas. En suma, el discurso proclama una cosa, intenta distorsionar la realidad mediante acciones y la realidad, como conjunto de objetos, es otra.

Pero una cosa era el discurso primero que había tomado forma y el lugar en el que lo había hecho, la revolución y la construcción subsiguiente, y otra su reaparición, en primer lugar y casi contemporáneamente, en su momento más brillante y efectivo, en otros lugares en los que una escena igualmente original debía y se suponía que podía tomar su propia forma puesto que así podían estarlo requiriendo condiciones objetivas 
para una revolución del mismo tipo, en Hungría o Alemania por ejemplo, en la década del 20 , preparadas para que la clase obrera tomara el poder ; quienes - seducidos, iluminados o enceguecidos por la coherencia del discurso soviético inicial, el de Lenín o Trotski sus voceros, que se abría y que había desencadenado tan concreta y eficazmente acciones sobre objetos presentes y futuros que podían ser semejantes a los propios - deseaban tener igual oportunidad sintiéndose autorizados por aquella realidad política y discursiva exitosa debían imaginar que una gesta semejante también sería posible para ellos. Pero no lo era : el único camino que se les abría era reproducir o imitar, como si eso bastara para llegar a un puerto semejante o igual, o sea una revolución que debía cambiar muchas cosas pero sobre todo la estructura del Estado.

Y si además de las dificultades que tiene la eventual y ya mencionada recuperación de una instancia originaria en otros lugares y con otros sujetos de enunciación se añade el peso del ya impuesto discurso estatalista, que se difunde y se impone en todas partes haciendo de los sujetos, que podemos llamar "utópicos", meros agentes de los intereses de un Estado, se puede comprender el alcance que tiene, en términos discursivos, la disociación entre las tres instancias constituyentes. Y también sus consecuencias, en particular la pérdida de su carácter interpretante, cualidad refulgente en el momento de la escena inicial, y el paulatino debilitamiento de sus capacidades de generar acciones así como se pierden de vista los objetos que dichas acciones deberían tender a considerar. Disociados los tres términos, los enunciadores del discurso que los debería reunir a los tres pierden credibilidad, parecen condenados a una eterna repetición que explica su aislamiento y la escasa fuerza de convencimiento que llegan a alcanzar.

Quizás este enfoque ayude a comprender el gradual y en apariencia irreversible achicamiento de las capacidades de movilización que padecen las izquierdas en todo el mundo; quizás no pierden virtudes explicativas de vicios o tropelías o defraudaciones en que incurren otros tipos de discursos y sus enunciadores que, correlativa e inversamente, mueven más que los que explican, denuncian o están presentes en las más diversas causas relativas a las injusticias sociales o a los enormes desequilibrios que destruyen la vida humana en todo el mundo. Pero eso no basta y, poco a poco, quienes creyeron en un discurso que venía disociado desde hacía décadas pero que se sostenía, y que reitera los modos que anteriormente le hacían creer que era imbatible, lo van abandonando y en muchas ocasiones se dejan llevar por los que previamente (en la época en que aun "creían") eran absolutamente antagónicos.

\section{RESÚMENES}

A partir de breves fragmentos discursivos de Lenin y sobre todo de Perón, el artículo se propone comentar un rasgo relevante del discurso, es decir, su capacidad de producir efectos no verbales. Se evocan: el esquema de instancias «objetos-acciones-discursos», la importancia de la identidad de los emisores, el peso de la Historia en la carga semántica de las emisiones verbales, y la noción de eficacia y coherencia de un discurso, que hay que ligar con las tres instancias 
mencionadas y también con factores contextuales. De todos esos elementos dependerá la capacidad de movilización de los discursos políticos.

L'article a comme objectif le commentaire d'un trait fondamental du discours, à savoir sa capacité de produire des effets non verbaux. Il prend comme exemple de brefs fragments du discours de Lénine et plus particulièrement de Perón. L'auteur évoque le schéma d'interactions entre "objets", "actions" et "discours", le poids de l'identité des émetteurs et la valeur déterminante de l'Histoire dans la sémantique des émissions verbales. Il commente également les notions d'efficacité et de cohérence discursive, qu'il faut relier aux trois paramètres indiqués de même qu'à des éléments contextuels. De tout cela dépendrait la capacité de mobilisation des discours politiques.

Focusing some short Lenin and Perón speech fragments, the article comments the capacity of producing non-verbal effects as a specific discourse feature. The author evokes the interaction pattern between "objects ", "actions " and "discourses " and the relevance of the speaker's identity. He comments as well the weight of History in the semantics of verbal utterances and the notions of efficacy and discourse coherence related to the above pattern and also to contextual elements. The capacity of mobilization of political speeches would depend on all that.

\section{ÍNDICE}

Mots-clés: discours politique, effets du discours, identité de l'émetteur, rhétorique, sémantique Palabras claves: discurso politico, efectos del discurso, identidad del emisor, retórica, semántica Keywords: political speech, discourse effects, speaker identity, rhetoric, semantics

\section{AUTOR}

\section{NOÉ JITRIK}

Universidad de Buenos Aires 